\title{
Psychiatric emergencies: assessing parents of dependent children
}

\author{
Barbara Hatfield, Jeni Webster and Hadi Mohamad
}

\begin{abstract}
Frameworks within which services are delivered to people with mental health problems neglect the specific needs of those with dependent chlidren. These children have been identifled as hoving risks to their development and well-being. A system of monitoring social assessments of mental health crisis is used to examine the characteristics of parents assessed in soven Local Authortiles across 3 calendar years. Parents of dependent children are underrepresented, and are more likely to be women and to suffer from affective psychosis. Ethnic minorties are overrepresented. Parents are less likely to be detained following assessment. Further work is needed to establish whether the needs of the family as a whole ore addressed.
\end{abstract}

Current policy frameworks, within which services for mentally ill people operate, have attempted to rationalise the access to and delivery of such services, to ensure that people in the greatest need are most likely to receive specialist services (Department of Health, 1994). The welldocumented reduction in psychiatric beds means that most people with mental health problems will live in the community most of the time. supported within the frameworks of the NHS and Community Care Act 1990 and the Care Programme Approach (DoH, 1994). For both approaches, targeting the greatest need has meant a focus upon severe and usually long-term psychiatric disorder and a high degree of social vulnerability as evidenced by poverty, lack of social supports, and risks to self or others.

Definitions of 'need' which focus upon severe psychiatric illness, social vulnerability and risk, tend to exclude individuals who are maintaining a close relationship and/or caring for dependent children. Publicised cases of homicides by psychiatric patients have generally involved relatively young men, experiencing severe psychiatric illness and social dislocation. Yet in the US, women with severe mental health problems have been estimated to be almost as likely as women in the general adult population to become mothers (Mowbray et al, 1995), although a substantial proportion of these experience the loss of their children to the public child care system (Blanche et al, 1994). For women in general, the care of young children has been consistently identified as a factor contributing to mental health vulnerability, particularly in relation to depression (Paykel, 1991). Of equal importance is the impact upon the development and well-being of children of the mental illness of their parents (Melhuish et al. 1988). The family group involving a parent with severe mental illness and dependent children is uniquely vulnerable, but there is no single service dedicated to their needs; mental health services tend to focus upon adult vulnerability, and while the Children Act authorises services to families of "children in need", the dearth of resources, and the targeting of abused children, may again serve to exclude this particular group of families from meaningful service input (Department of Health, 1995).

A further route to receipt of specialist psychiatric services is afforded via responses to psychiatric emergencies, which of their nature do not fall neatly into predetermined priorities. Psychiatric emergencies have been classified into three broad groups: people in acute psychosocial crisis, people with acute psychiatric conditions, and people with chronic psychotic conditions living in the community and experiencing periodic crisis (Katschnig \& Konieczna, 1990). While these three groups overlap, they do offer a useful framework for analysis. Parents of dependent children with mental health difficulties are probably more likely to present in the first two categories than the third, while continuing service targeting may be prioritised to the third group.

The findings reported in this paper are taken from an ongoing system which monitors Approved Social Work assessments under the 1983 Mental Health Act. Approved Social Workers are required to make application for compulsory admission under the Act, and are directed to interview the patient and make an assessment of his circumstances; they therefore obtain a social assessment at the point of crisis when compulsory admission is under consideration. The focus of interest in this paper is the parental status of people assessed.

\section{The study}

The Mental Health Act 1983 monitoring system currently operates in nine Local Authorities, and 
has been running in five of these for five calendar years (Hatfield et al, 1992). Each time an Approved Social Worker is asked to assess a patient with a view to making application under the Act, a monitoring form is completed providing demographic information, diagnosis where available, and information about the process and outcome of the assessment. Data is therefore available on all incidents of compulsory detention in these Authorities, including those involving patients already on wards when assessed (informal or Section 5 patients). Information is also included on those assessed but not detained as a result. Information on parental status has only routinely been collected for three years, 1992-94 inclustve, and this is the time period reported. Data is analysed using SPSS. For the purposes of this paper, seven Authorities are used, all Metropolitan Boroughs of Manchester. Over the three years, 3554 assessments were recorded by Approved Social Workers, of these 551 (15.5\%) involved adults living in households with their children.

\section{Findings}

Characteristics of the people assessed under the Act

Gender. Fifty-four per cent of all assessments involved women, but this is a diminishing proportion, and for the first time in 1994, men were overrepresented in relation to their numbers in the general adult population of the Authorities: in this year, $48.7 \%$ of assessments involved men (general adult population of the seven Authorities 48.0\% men (Office of Population Censuses and Surveys, 1992)). Further analysis indicates that the change is largely accounted for by an increase in the number of assessments on younger men. with severe disorders, who tend to be repeatedly assessed. Nationally, most recent (1991/92) avallable data shows that just over half of all admission episodes in relation to mental illness involved women (Department of Health, 1995).

Age. Analysis of the age structure of the assessed population reveals that more assessments of men than women took place in the younger age groups; in 1994, $70.7 \%$ of all assessments on men involved men aged 44 years or less, compared with $53.7 \%$ of assessments on women. This clearly affects the proportion of parents of dependent children represented.

Employment. Fifty-four per cent of all assessments were recorded on people described as 'not in employment', and a further $21.3 \%$ on people described as 'retired'. In the Northwest as a whole, $10.2 \%$ of the adult population were recorded as unemployed in 1994 (Central
Statistical Office, 1995). Economic and social vulnerability is reflected in these proportions.

Housing and living group. Thirty per cent of all assessments were recorded on people living in owner-occupied housing; $64.2 \%$ of all households in Greater Manchester are owner-occupied (Office of Population Censuses and Surveys, 1991).

Thirty-four per cent of assessments involved people living alone - this was the most common living situation. One-quarter involved people living with a current partner. Women were more likely than men to be, or to have been, married $64.6 \%$ compared with $31.2 \%$. For women, this is similar to the proportion in mental lliness admission episodes nationally, however, a higher proportion of single men is evident in the compulsory admissions.

Eleven per cent of assessments involved people living in households with a partner and at least one child (under 18 years). A further $4.6 \%$ involved people living alone with a dependent child. Nationally, $25 \%$ of all households consist of a couple with dependent children, and a further $7 \%$ consist of a lone parent with dependent children (Central Statistical Office, 1995). People with dependent children are therefore underrepresented among those assessed under the provisions of the Mental Health Act. Information on parental status is not routinely recorded in national admission episode data.

Ethnic minorities. Ninety per cent of the assessments were carried out in relation to people described as European/Caucasian. Numbers of assessments on people from ethnic minorities were as in Table 1.

Diagnosis. A little over a fifth of assessments were recorded as involving people where the diagnosis was not known or not recorded. Of the remainder, $33.2 \%$ had a diagnosis of schizophrenia and $29.5 \%$ had a diagnosis of affective

Table 1. Ethnic background of people assessed $(n=3533$, missing data $=21$ )

\begin{tabular}{lrl}
\hline Ethnic group & Number (\%) \\
\hline European/Caucasian & $3177(90.4)$ \\
African-Caribbean & 125 & $(3.5)$ \\
African & 9 & $(0.3)$ \\
Pakistani & 95 & $(2.7)$ \\
Bangladeshi & 11 & $(0.3)$ \\
Indian & 40 & $(1.1)$ \\
Chinese & 4 & $(0.1)$ \\
Other Asian & 7 & $(0.2)$ \\
Other ethnic minority & 21 & $(0.6)$ \\
Other & 28 & $(0.8)$ \\
Not known & 16 & $(0.5)$ \\
\hline
\end{tabular}


psychosis. A further $8 \%$ had 'other psychosis' recorded. For national mental illness admission episodes (1991-92) the proportions of people with a diagnosis of psychotic illness are much lower (schizophrenia 15.4\%, affective psychosis $16.6 \%$ and other psychoses $16.5 \%)$. The group assessed under the Act are characterised by more severe psychiatric illnesses.

\section{Mental Health Act assessments and parents of dependent children}

Of the 551 assessments involving parents living with their dependent children (defined as aged under 18 years), $72.1 \%$ involved women. Sixtyfive per cent of all parents were aged 40 years or less.

Parents tended to be slightly more economically advantaged than the assessed group as a whole more described themselves as 'employed' (17.5\%) and more lived in owner-occupation (42.5\%). However, they are still markedly disadvantaged in relation to the general population.

Ethnic minorities. The overrepresentation of ethnic minority people in Mental Health Act assessments is even more marked among assessments of parents, which is expected given the much younger age structure of ethnic minority populations. One-quarter of all assessments involving ethnic minority people involved parents of dependent children - significantly more than white people assessed $\left(\chi^{2}=29.10\right.$, d.f. $=1$, $P<0.001$ ).

The two largest ethnic minority groups in the system are African-Caribbeans $(n=125)$ and Pakistanis ( $n=95)$. Within these groups, assessments of African-Caribbean women are the most likely to involve parents of dependent children (37.5\%), followed by assessments of Pakistani men $(32.7 \%)$.

Diagnosis. Of assessments involving parents, where the diagnosis was known or recorded, just over $70 \%$ had a diagnosis of psychotic illness very similar to the group as a whole. However, within the psychotic group, those who were parents were significantly more likely to have a diagnosis of affective psychosis (see Table 2).

Outcome. Assessments under the Mental Health Act 1983 do not inevitably result in application for detention. Sometimes informal admission is appropriate, and sometimes referrals are made to the services where hospital admission can be avoided altogether. Of the 3554 assessments analysed here, $2391(67.3 \%)$ culminated in application for detention, the remainder being either informally admitted or not admitted. Parents of dependent children were significantly
Table 2. Diagnoses of psychotic illness in parents and non-parents assessed $(n=1896 ;$ missing data $=57 ; \chi^{2}=15.33$, d.f. $=2, P<0.001$ )

\begin{tabular}{lcc}
\hline & $\begin{array}{l}\text { Parents } \\
n \text { (\%) }\end{array}$ & $\begin{array}{l}\text { Non-parents } \\
n \text { (\%) }\end{array}$ \\
\hline Schizophrenia & $115(36.5)$ & $767(48.5)$ \\
Affective psychosis & $159(50.5)$ & $639(40.4)$ \\
Other psychosis & $41(13.0)$ & $175(11.1)$ \\
Total & 315 & 1581 \\
\hline
\end{tabular}

less likely to be detained following assessment $\left(\chi^{2}=4.97\right.$, d.f. $\left.=1, P \leqslant 0.05\right)$.

\section{Comment}

People reaching the specialist psychiatric services, who are responsible for the care of dependent children, merit particular attention to address the vulnerability of the family unit as a whole.

The evidence of this paper is that among the group assessed under the Mental Health Act, parents of dependent children are underrepresented, and those that are represented are significantly less likely to be detained following assessment. This is possibly because they are somewhat better resourced socially or economically, or have some of the skills needed to maintain supportive relationships. There may also be a greater concern in the decision-making of professionals to maintain the family as a unit, and treat at home.

Our prime concern is that professionals involved in mental health crisis should be aware of the complexity of need of family units with children. and the potentially serious and long-term impact of parental mental illness upon young children. Psychiatric emergencies involving parents must be highly disturbing to children, unless adequate alternative supports are available. Children of lone parents may be at particular risk.

Our evidence is that parents assessed under the Act are more likely to be women, the major diagnosic category is affective psychosis, and assessments involving ethnic minorities are more likely to include parents. From the point of view of social assessment, this latter point again highlights the complexity of assessing parent-child needs where issues of language, culture, and the ethnic sensitivity of services are also considerations. The concerns outlined are in the process of being further examined.

\section{Acknowledgement}

Grateful thanks to the Approved Social Workers of the seven Northwest Metropolitan Boroughs for their continuing recording of Mental Health Act assessments. 


\section{References}

Blanche, A. K., Nicholson, J. \& PURCel,. J. (1994) Parents with severe mental illness: the need for human services integration. The Journal of Mental Health Administration. 21, 388-396.

Central Statistical Office (1995) Social Trends. London: HMSO.

DEPARTMENT OF HEALTH (1994) The Health of the Nation. Key Area Handbook: Mental Illness (2nd edition). London: HMSO.

- (1995) Child Protection: Messages from Research. Studies in Child Protection. London: HMSO.

Department of Health Statistics Division (1995) Mental Health in England. London: Department of Health.

HATfield, B., HuXIEY, P. \& MOHAMAD, H. (1992) The 1983 Mental Health Act in five Local Authorities: a study of the practice of Approved Social Workers. The International Journal of Social Psychiatry. 38, 189-207.

KATSCHNIG, H. \& KONIECZNA. T. (1990) Innovative approaches to delivery of emergency services in Europe. In Mental Health Care Delivery: Innovations, Impediments and Implementation (eds I. Marks \& R. Scott). Cambridge: Cambridge University Press.

Melhuish, E.. Gambles, C. \& Kumar, R. (1988) Maternal mental illness and the mother-infant relationship. In
Motherhood and Mental Illness 2. Causes and Consequences (eds R. Kumar \& I. F. Brockington). London: Butterworth \& Co.

MOWBRAY, C. T., OYSERMAN, D. ZEMENCUK, J. K. et al (1995) Motherhood for women with serious mental illness: pregnancy, childbirth and the postpartum period. American Journal of Orthopsychiatry, 65, 21-38.

OfFICE OF POPULATION CENSUSES AND SURVEYS (1992) 1991 Census. Greater Manchester County Monitor. London: Government Statistical Service.

PAYKEL, E. S. (1991) Depression in women. British Journal of Psychiatry. 168 (suppl. 10), 22-29.

*Barbara Hatfield, Lecturer in Psychiatric Social Work, Jeni Webster, Lecturer in Psychiatric Social Work; and Hadi Mohamad, Senior Statistician, Mental Health Social Work Research and Staff Development Unit, Department of Psychiatry. Manchester University, Oxford Road, Manchester M13 9PL

*Correspondence 